\title{
Effects of Exogenous Melatonin on Photosynthetic Physiology of Lettuce Seedlings under Salt Stress
}

\author{
Yongdong Xie ${ }^{1, a}$, Guochao Sun²,b, Huiping Liao ${ }^{3, \mathrm{c}}$ and Yi Tang ${ }^{2, \mathrm{~d}^{*}}$ \\ ${ }^{1}$ College of Horticulture, Sichuan Agricultural University, Chengdu, Sichuan, China \\ ${ }^{2}$ Institute of Pomology and Olericulture, Sichuan Agricultural University, Chengdu, Sichuan, China \\ ${ }^{3}$ Sichuan HuaSheng Agricultural Co., LTD., Mianzhu, Sichuan, China \\ axydcom@sina.cn, b6183090@qq.com, c761329244@qq.com, d95459425@qq.com \\ ${ }^{*}$ Corresponding author. Yongdong Xie and Guochao Sun contributed equally to this work.
}

Keywords: Melatonin; Lettuce; Salt stress; Photosynthetic physiology

\begin{abstract}
The glass lettuce was made as material, the effect of different concentrations $(0,50,100$, 150, $200 \mu \mathrm{mol} \cdot \mathrm{L}^{-1}$ ) of exogenous melatonin on photosynthetic pigments and photosynthetic characteristics of lettuce seedlings under salt stress was studied. The results showed that when the concentration of melatonin was less than $100 \mu \mathrm{mol} \cdot \mathrm{L}^{-1}$, the chlorophyll content, carotenoid content, net photosynthetic rate, stomatal conductance, and transpiration rate in leaves of lettuce seedlings were all increased along with the increased of melatonin concentration. When the concentration of melatonin continued to increase, all indicators decreased. But the opposite trend of intercellular carbon dioxide was presented. Therefore, spraying melatonin could increase the resistance of lettuce under salt stress, and the best effect was obtained when the concentration was $100 \mu \mathrm{mol} \cdot \mathrm{L}^{-1}$.
\end{abstract}

\section{Introduction}

Facilities cultivation has become an important industry for promoting agricultural modernization, long-term cover cultivation will lead to problems such as salt accumulation on the surface and secondary salinization of soil, which seriously affect the cultivation of vegetables [1]. More studies have shown that photosynthetic parameters, osmotic potential, water potential, transpiration rate, leaf temperature, and relative water content of the plant changes under salt stress [2]. Salt stress also affects components of photosynthetic organs, such as enzymes, photosynthetic pigments, thylakoid membrane proteins, and membrane lipids. Changes in these parameters depend on the degree and duration of salt stress [3], and different plant species [4].

Melatonin is a kind of conservative small molecule material in the process of biological evolution. It has a strong anti-oxidant effect and is widely found in plants [5]. Melatonin has a wide range of physiological functions in plants, and many researches about exogenous melatonin regulate plant growth and development and stress resistance were conducted. Szafrańska found that melatonin treatment alleviated paraquat-mediated stress damage to photosynthetic apparatus in peas [6]. Studies by Liu showed that melatonin treatment enhanced photosynthetic performance and increased antioxidant capacity of tomato seedlings under drought stress [7]. Melatonin may improve the plant resistance by inhibiting the ROS production in chloroplast and regulate photosynthetic electron transport and D1 protein synthesis $[8,9]$. With the increase of soil secondary salinization in facilities, the growth and development of lettuce has been greatly affected. Therefore, this study explored the effects of exogenous melatonin on photosynthetic physiology of lettuce under salt stress.

\section{Materials and Methods}

Materials. The experiments were conducted at Sichuan Agricultural University $\left(30^{\circ} 42^{\prime} \mathrm{N}\right.$, $\left.103^{\circ} 51^{\prime} \mathrm{E}\right)$, Wenjiang, China. The lettuce seeds named 'glass lettuce'were purchased from Chengdu, China. Melatonin was purchased from Sigma-Aldrich (St. Louis, MO, USA). All chemicals used in 
experiments were of analytical grade.

Experimental Design. The plump lettuce seeds were chose and sterilized with $1.2 \%$ sodium hypochlorite solution for $10 \mathrm{~min}$, rinsed with deionized water three times, placed in a petri dish covered with wet filter paper, and placed in dark artificial climate incubator at $22{ }^{\circ} \mathrm{C}$ for germination. When the seeds piped, the germinated seeds were selected and sown them into the pots filled with the substrate. The size of the pots was $21 \mathrm{~cm} \times 20 \mathrm{~cm}$ (diameter $\times$ height). The ratio of the substrate was vermiculite: perlite $=1: 1$, the pots were placed in a plastic greenhouse, and 1/2 Hoagland nutrient solution was poured every 2 days. After the second true leaf of lettuce was fully developed, the lettuce seedlings with the same growing trend were treated with salt stress with Hoagland nutrient solution containing $50 \mathrm{mmol} \cdot \mathrm{L}^{-1} \mathrm{NaCl}$, and were poured every 2 days, $20 \mathrm{ml}$ each time, until the end of the experiment and daily replenished water depend on the weather. When the three true leaves of lettuce are fully spread, the four seedlings with the same growth were retain in per pot. Different concentration of melatonin solution with 0 (CK, fresh water treatment), 50, 100, $150,200 \mu \mathrm{mol} \cdot \mathrm{L}^{-1}$ was sprayed on the leaves at 18:00 until leaf dripping, once every two days and for a total of 3 times. Each treatment was repeated 6 times for a total of 30 pots. The photosynthetic rate and photosynthetic pigment content of lettuce were determined 30 days after sprayed melatonin.

Statistic analyses. Statistical analyses were performed using SPSS 13.0 statistical software (IBM, Chicago, IL, USA). Data were analyzed by one-way ANOVA with least significant difference (LSD) at a $5 \%$ confidence level.

\section{Results and Discussion}

Photosynthetic Pigment Content in Lettuce Seedlings under Salt Stress. As shown in Table 1, the contents of chlorophyll and carotenoids in lettuce leaves after applied melatonin were higher than those in the control. With the increase of melatonin concentration, the total chlorophyll a, chlorophyll $\mathrm{b}$ and total chlorophyll increased first and then decreased. The maximum value was reached when the melatonin concentration was $100 \mu \mathrm{mol} \cdot \mathrm{L}^{-1}$, which was respectively increased by $58.5 \%, 41.7 \%$, and $54.7 \%$ compared to the control. When compared with $100 \mu \mathrm{mol} \cdot \mathrm{L}^{-1}$, although all values decreased when the melatonin concentration was $150 \mu \mathrm{mol} \cdot \mathrm{L}^{-1}$ and $200 \mu \mathrm{mol} \cdot \mathrm{L}^{-1}$, remained significantly higher than the control. However, the carotenoid content was significantly higher than that of the control only when the melatonin concentration was $100 \mu \mathrm{mol} \cdot \mathrm{L}^{-1}$ and the other three treatment were not significantly different from the control. The leaf chlorophyll $\mathrm{a} / \mathrm{b}$ with spraying melatonin was higher than that of the control. When the melatonin concentration was 100 $\mu \mathrm{mol} \cdot \mathrm{L}^{-1}$, it peaked and then decreased, but the difference was not significant.

Table 1 Photosynthetic pigment content in lettuce seedlings under salt stress

\begin{tabular}{|c|c|c|c|c|c|}
\hline $\begin{array}{c}\text { Melatonin } \\
\text { Concentration } \\
/\left(\mu \mathrm{mol} \cdot \mathrm{L}^{-1}\right)\end{array}$ & $\begin{array}{c}\text { Chlorophyll a } \\
/\left(\mathrm{mg} \cdot \mathrm{g}^{-1} \mathrm{FW}\right)\end{array}$ & $\begin{array}{c}\text { Chlorophyll b } \\
/\left(\mathrm{mg} \cdot \mathrm{g}^{-1} \mathrm{FW}\right)\end{array}$ & $\begin{array}{c}\text { Total Chlorophyll } \\
/\left(\mathrm{mg} \cdot \mathrm{g}^{-1} \mathrm{FW}\right)\end{array}$ & $\begin{array}{c}\text { Chlorophyll a/b } \\
/\left(\mathrm{mg} \cdot \mathrm{g}^{-1} \mathrm{FW}\right)\end{array}$ & $\begin{array}{c}\text { Carotenoids } \\
/\left(\mathrm{mg} \cdot \mathrm{g}^{-1} \mathrm{FW}\right)\end{array}$ \\
\hline 0 & $0.41 \pm 0.03 \mathrm{c}$ & $0.12 \pm 0.01 \mathrm{c}$ & $0.53 \pm 0.02 \mathrm{c}$ & $3.42 \pm 0.01 \mathrm{a}$ & $0.24 \pm 0.014 \mathrm{~b}$ \\
\hline 50 & $0.51 \pm 0.01 \mathrm{~b}$ & $0.14 \pm 0.01 \mathrm{~b}$ & $0.65 \pm 0.01 \mathrm{~b}$ & $3.64 \pm 0.007 \mathrm{a}$ & $0.24 \pm 0.012 \mathrm{~b}$ \\
\hline 100 & $0.65 \pm 0.01 \mathrm{a}$ & $0.17 \pm 0.04 \mathrm{a}$ & $0.82 \pm 0.04 \mathrm{a}$ & $3.82 \pm 0.15 \mathrm{a}$ & $0.27 \pm 0.002 \mathrm{a}$ \\
\hline 150 & $0.54 \pm 0.01 \mathrm{~b}$ & $0.15 \pm 0.02 \mathrm{~b}$ & $0.69 \pm 0.06 \mathrm{~b}$ & $3.60 \pm 0.12 \mathrm{a}$ & $0.25 \pm 0.004 \mathrm{~b}$ \\
\hline 200 & $0.52 \pm 0.01 \mathrm{~b}$ & $0.15 \pm 0.01 \mathrm{~b}$ & $0.67 \pm 0.03 \mathrm{~b}$ & $3.46 \pm 0.12 \mathrm{a}$ & $0.24 \pm 0.021 \mathrm{~b}$ \\
\hline
\end{tabular}

Note: there is a significant difference between 0.05 levels of different letters, the same as following tables.

Photosynthesis of Lettuce Seedlings under Salt Stress. As shown in Fig. 1, with the increase of melatonin concentration, the net photosynthetic rate, stomatal conductance and transpiration rate of 
lettuce seedlings under salt stress first increased and then decreased. They peaked when the concentration of melatonin reached $100 \mu \mathrm{mol} \cdot \mathrm{L}^{-1}$, although they decreased when the concentration of melatonin higher than $100 \mu \mathrm{mol} \cdot \mathrm{L}^{-1}$, it was still significantly higher than the control. However, the change trend of intercellular $\mathrm{CO}_{2}$ concentration in each concentration treatment was opposite to that of net photosynthetic rate, and the values of each treatment were significantly lower than the control.
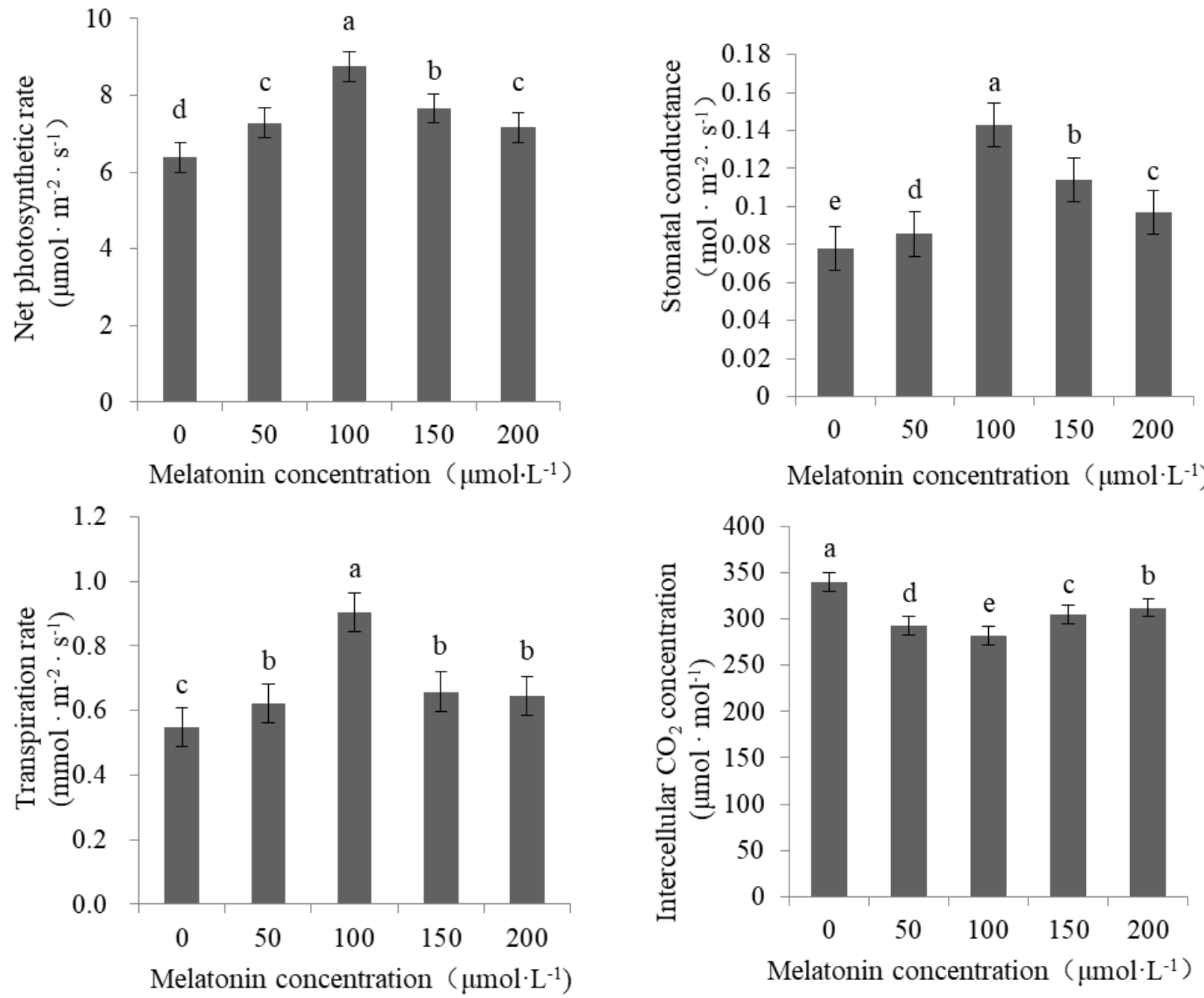

Fig. 1 Photosynthesis of lettuce seedlings under salt stress

\section{Conclusions}

There is a close positive correlation between photosynthetic pigment content and photosynthesis in plants. Studies have shown that low concentrations of melatonin significantly increased the content of chlorophyll and carotenoids in lettuce under salt stress. Meanwhile, application of melatonin increased the stomatal conductance and reduced the intercellular $\mathrm{CO}_{2}$ concentration in leaves of lettuce seedlings, which indicated that certain concentration of melatonin decreased the inhibition of photosynthesis due to stomatal factors by increasing stomatal conductance. In addition, the transpiration rate of plant reflects the strength of transpiration, and strong transpiration can accelerate plant absorb water and reduce salt damage. In this study, spraying melatonin increased the transpiration rate of lettuce seedlings, indicating that melatonin relieved salt damage by accelerating the water absorption of plants. In conclusion, $100 \mu \mathrm{mol} \cdot \mathrm{L}^{-1}$ melatonin significantly increased stomatal conductance, transpiration rate, net photosynthetic rate of lettuce under salt stress. 


\section{Acknowledgements}

This work was financially supported by the Application Infrastructure Project of Science and Technology Department of Sichuan Province (2016JY0258).

\section{References}

[1] R. Farhoudi: Acta Horticulturae Vol. 971(2013), p.127-135.

[2] P. Sudhir and S. D. S. Murthy: Photosynthetica Vol. 42(2004), p. 481-486.

[3] A. Lakshmi, S. Ramanjulu and K. Veeranjaneyulu: Photosynthetica, Vol. 32(1996), p.285-289.

[4] A. N. Misra, S. M. Sahu and M. Misra: Biologia Plantarum, Vol. 39(1997), p.257-262.

[5] R. D. Hardelan: Frontiers in Plant Science, Vol. 7(2016), p. 198.

[6] K. Szafrańska, R. J. Reiter and M. M. Posmyk: Frontiers in Plant Science, Vol. 7(2016), p.1663.

[7] J. Liu, W. Wang and L. Wang: Plant Growth Regulation, Vol. 77(2015), p.317-326.

[8] H. Zhao, L. Ye and Y. Wang: Frontiers in Plant Science, Vol. 7(2016), p. 1814.

[9] X. Zhou, H. Zhao and K. Cao: Frontiers in Plant Science, Vol. 7(2016), P. 1823. 